\title{
Assessment of right ventricular function using cardiovascular magnetic resonance in patients with type 2 diabetes mellitus
}

\author{
Yongning Shang ${ }^{1,2}$, Yulin Zhang ${ }^{3}$, Weiling Leng ${ }^{4}$, Xiaotian Lei ${ }^{4}$, Liu Chen ${ }^{4}$, Xiaoyue Zhou ${ }^{5}$, Ziwen Liang ${ }^{4}$, \\ Jian Wang ${ }^{2}$ \\ ${ }^{1}$ Department of Ultrasound, Southwest Hospital, Army Medical University (Third Military Medical University), Chongqing, China; ${ }^{2}$ Department \\ of Radiology, Southwest Hospital, Army Medical University (Third Military Medical University), Chongqing, China; ${ }^{3}$ Department of Cardiology, \\ Xinqiao Hospital, Army Medical University (Third Military Medical University), Chongqing, China; ${ }^{4}$ Department of Endocrinology, Southwest \\ Hospital, Army Medical University (Third Military Medical University), Chongqing, China; ${ }^{5}$ Siemens Healthineers Ltd., Shanghai, China
}

Contributions: (I) Conception and design: Y Shang, J Wang; (II) Administrative support: J Wang; (III) Provision of study materials or patients: W Leng, X Lei, L Chen, Z Liang; (IV) Collection and assembly of data: Y Shang, Y Zhang; (V) Data analysis and interpretation: Y Shang, Y Zhang, J Wang; (VI) Manuscript writing: All authors; (VII) Final approval of manuscript: All authors.

Correspondence to: Jian Wang. Department of Radiology, Southwest Hospital, Army Medical University (Third Military Medical University), 30 Gaotanyan Street, Shapingba District, Chongqing, China. Email: wangjian_811@yahoo.com.

Background: Accurate evaluation of right ventricular (RV) function is always difficult due to its irregular shape and movement. Many indices have been proposed to assess RV function, but none have been universally accepted. This study evaluated RV function in type 2 diabetes mellitus (T2DM) patients using long-axis strain (LAS) and other traditional indices.

Methods: Fifty-seven patients with T2DM and 39 healthy controls were prospectively enrolled. Fourchamber cardiovascular magnetic resonance (CMR) and RV short-axis cine images were obtained from all participants to measure the tricuspid annular plane systolic excursion (TAPSE), RV ejection fraction (EF), peak longitudinal strain (PLS) and four LAS indices. The inter-and intraobserver variabilities were also calculated.

Results: Compared with healthy controls, T2DM was associated with a decreased LAS (apex/lateral wall) $(-17.4 \% \pm 4.2 \%$ vs. control, $-19.7 \% \pm 3.7 \%, \mathrm{P}=0.008)$ and LAS (apex/middle point) $(-17.5 \% \pm 4.5 \%$ vs. control, $-19.5 \% \pm 3.9 \%, \mathrm{P}=0.026$ ), but both groups had a similar LAS (RV/lateral wall) and LAS (RV/middle point) (all $\mathrm{P}>0.05$ ). After adjustments for age and body mass index, a significant difference was observed only for LAS (apex/lateral wall) $(\mathrm{P}=0.028)$. There were no significant differences in the TAPSE, RVEF and PLS (all $\mathrm{P}>0.05$ ). LAS (apex/lateral wall) correlated with the TAPSE ( $\mathrm{r}=-0.723, \mathrm{P}<0.001)$, RVEF $(\mathrm{r}=-0.270, \mathrm{P}=0.008)$ and PLS $(r=0.210, P=0.040)$. The inter- and intraobserver variability of the LAS (apex/lateral wall) were lower than the other three LAS indices.

Conclusions: Compared with traditional RV function indices, such as the TAPSE, RVEF and PLS, LAS is easy to obtain and shows high repeatability. LAS (apex/lateral wall) may provide a more sensitive T2DMrelated RV dysfunction index.

Keywords: Type 2 diabetes mellitus (T2DM); right ventricular (RV) function; long-axis strain (LAS); tricuspid annular plane systolic excursion (TAPSE)

Submitted Apr 07, 2021. Accepted for publication Aug 24, 2021.

doi: 10.21037/qims-21-376

View this article at: https://dx.doi.org/10.21037/qims-21-376 


\section{Introduction}

Type 2 diabetes mellitus (T2DM) is one of the most common chronic diseases, increasing its prevalence (1). Many complications in various bodily systems accompany T2DM. T2DM and its complications seriously affect people's health and greatly increase the social burden of this disease. Cardiovascular adverse events represent some of the main complications and causes of death in T2DM. Even in the absence of coronary atherosclerotic heart disease and hypertension, T2DM can lead to myocardial structural and functional damage, termed diabetic cardiomyopathy.

Compared with the left ventricle, the right ventricle has an irregular shape and movement. Therefore, it is difficult to evaluate right ventricular (RV) function accurately. However, RV dysfunction is associated with limited exercise capacity and it significantly affects prognosis in many diseases $(2,3)$. At present, many indices have been proposed to evaluate RV function, but none of them have been universally accepted. Thus, a reliable way to accurately assess RV function is urgently needed.

Cardiovascular magnetic resonance (CMR) cine imaging has been widely embraced to evaluate both left ventricular (LV) and RV function and structure (4). However, it is time consuming to manually delineate the epicardial and endocardial boundaries on the short axis cine images to derive the LV/RV function parameters. Besides, due to the irregular shape of the right ventricle, the repeatability of the measurement is poor (5). Therefore, long axis functions are widely used to evaluate the RV function. Tricuspid annular plane systolic excursion (TAPSE), one of the most commonly used RV long-axis function indices, is generally measured in apical four-chamber sections using the echocardiography M-mode. According to its definition, CMR-TAPSE can also be measured in a four-chamber cine $(6,7)$. As an absolute value, the measurement of TAPSE is simple. However, because it is affected by many factors, its sensitivity and specificity concerning RV function are poor (8). Recently, long-axis strain (LAS) has been proposed as an accurate and simple measure of RV function in various disease states (9). The calculation of LAS, based on the RV long axis length systolic shortening rate on cine images, is convenient (10). However, it is unclear whether LAS and other RV indices are changed in patients with T2DM.

Therefore, this study aimed to evaluate RV function in patients with T2DM using LAS and other traditional indices.

\section{Methods}

\section{Study subjects}

The study was conducted in accordance with the Declaration of Helsinki (as revised in 2013). The study was approved by the Ethics Committee of the First Affiliated Hospital of Third Military Medical University (scientific research no. 50; approval date: May 11, 2016), and informed consent was obtained from all patients.

Sixty-one patients were prospectively enrolled between June 2015 and March 2018. The inclusion criteria were as follows: (I) an initial diagnosis of T2DM according to World Health Organization criteria (11); (II) no hypertension (resting systolic/diastolic blood pressure $<140 / 80 \mathrm{mmHg}$ ); and (III) no history of cardiovascular disease or chest pain. The exclusion criterion was any standard contraindication to MRI. Forty controls were recruited from the community with the following criteria: (I) no T2DM; (II) no hypertension; (III) normal blood cholesterol and triglycerides; and (IV) no history of cardiovascular disease or chest pain.

\section{Anthropometric and biochemical examinations}

All participants underwent height, weight and blood pressure measurements. Blood samples were obtained approximately half an hour before the CMR scanning. They were immediately sent to the Department of Clinical Laboratory for analysis of total cholesterol, triglycerides, high-density lipoprotein cholesterol (HDL-C), low-density lipoprotein cholesterol (LDL-C), glucose and glycated hemoglobin (HbA1c).

\section{Cardiac magnetic resonance protocols}

All CMR scanning was performed on a 3.0T MR scanner (MAGNETOM Trio, Siemens Healthcare, Erlangen, Germany) with a combination of a 12-channel body array coil and the spine coil. An electrocardiogram-gated and breath-hold balanced steady-state free precession (bSSFP) sequence was used to obtain the short-axis cine images (covering the entire LV) and four-chamber long-axis cine images with the following parameters: slice thickness $=6 \mathrm{~mm}$, slice gap $=1.5 \mathrm{~mm}$, field of view $=325 \times 400 \mathrm{~mm}^{2}$, matrix $=179 \times 256$, repetition time/echo time $(\mathrm{TR} / \mathrm{TE})=59.22 / 1.45 \mathrm{~ms}$ and 25 reconstructed phases per cardiac cycle. 


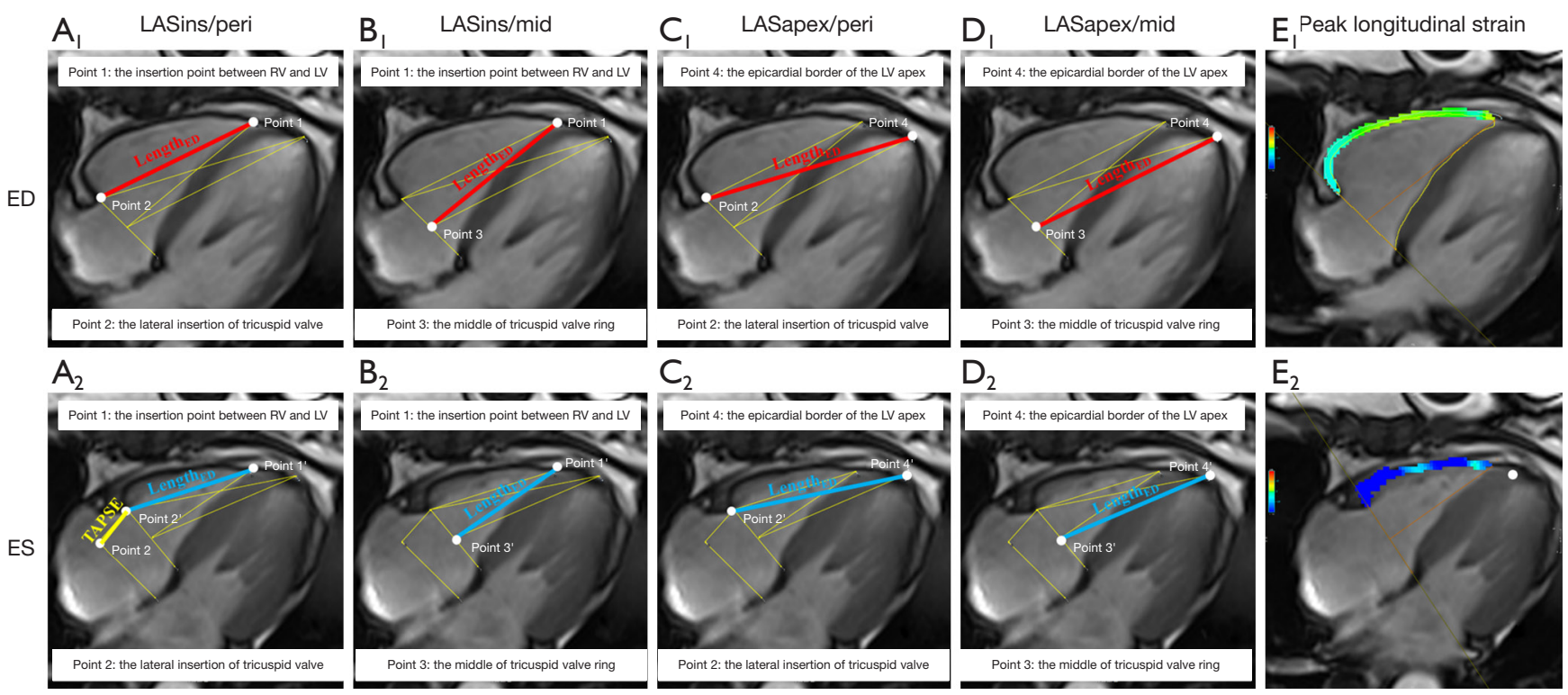

Figure 1 Schematic diagram for right ventricular longitudinal function measurements. Illustration of the four different LAS measurements $(\mathrm{A}-\mathrm{D})$, where LAS measurement $=\left(\right.$ Length $_{\mathrm{ES}}-$ Length $\left._{\mathrm{ED}}\right) /$ Length $_{\mathrm{ED}} \times 100 \%$ : LASins/peri: (A) Point 1 (1') is the insertion point between the $\mathrm{RV}$ and $\mathrm{LV}$; Point $\left.2{ }^{\prime} 2^{\prime}\right)$ is the lateral insertion of the tricuspid valve; Length $\mathrm{ED}$, point 1 to point 2 (A1); Length ${ }_{\mathrm{ES}}$, point $1^{\prime}$ to point 2 ' (A2); LASins/mid: (B) Point 1 (1') is the insertion point between the RV and LV; Point 3 (3') is the middle of the tricuspid valve ring; Length ${ }_{\mathrm{ED}}$,

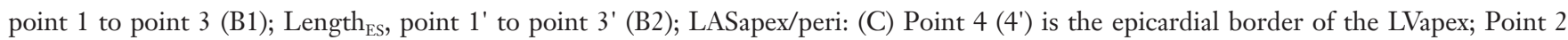

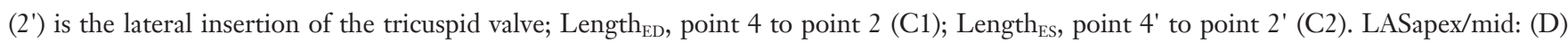
Point 4 (4') is the epicardial border of the LVapex; Point 3 (3') is the middle of the tricuspid valve ring; Length ${ }_{\mathrm{ED}}$, point 4 to point 3 (D1); Length $_{\mathrm{ES}}$, point 4' to point 3' (D2). CMR-TAPSE was the distance between the tricuspid annulus during diastole (Point 2, A1) and during systole (Point 2, A2). Peak longitudinal strain measured by feature tracking on four-chamber long-axis cine image (E). LAS, long-axis strain; $\mathrm{RV}$, right ventricular; LV, left ventricular; CMR, cardiovascular magnetic resonance; TAPSE, tricuspid annular plane systolic excursion.

\section{$R V$ function measurements}

All offline measurements were performed on commercially available software [cvi42, version 5.11 .3 (1548), Circle Cardiovascular Imaging Inc., Calgary, Alberta, Canada].

\section{TAPSE}

Generally, the echocardiography M-mode was used to obtain TAPSE (12). CMR-TAPSE was the distance between the tricuspid annulus during diastole and systole on CMR four-chamber cine images (Figure 1A).

\section{LAS}

LAS measurements were obtained on four-chamber images according to the following formula: LAS $=\left(\right.$ length $_{\mathrm{ES}}$ - length ED $) /$ length ED $\times 100 \%$ (9). Measurements of four different lengths at end-diastolic (ED) and the corresponding lengths at ES were obtained from four different points: Point 1: the insertion point between the RV and LV; Point 2: the lateral insertion of the tricuspid valve; Point 3: the middle of the tricuspid valve ring; Point 4: the epicardial border of the LVapex (Figure 1A-1D).

\section{Two-dimensional feature tracking}

Endocardial and epicardial contours of the four-chamber and mid-ventricular short-axis cine images at the end-diastole phase were manually traced (Figure $1 E$ ). The software was able to track the motion at all other phases automatically. All tracked contours were checked and when poorly tracked, the data were excluded. Subsequently, the RV global longitudinal, circumferential and radial strains, as well as the peak systolic and diastolic strain rates, were obtained.

\section{RV global function}

The endocardial and epicardial contours of all short axes 
covering the RV at the ED and ES phases were manually delineated to obtain the RV, ED volume index (EDVi), ES volume index (ESVi), stroke volume index (SVi), ejection fraction (EF) and RV cardiac index (RVCI). The shortening percentage of the ED diameter (EDD) was also measured on the mid-ventricular short-axis cine images.

\section{Inter- and intraobserver reproducibility}

To assess interobserver reproducibility, images of twenty randomly selected participants (control subjects, five males and five females; T2DM patients, five males and five females) were independently analyzed by Shang Y and Zhang Y. For intraobserver reproducibility, Shang Y reanalyzed the images after 2 weeks.

\section{Statistical analysis}

SPSS (version 21.0, SPSS Inc., Chicago, IL, USA) was used for the statistical analysis and GraphPad Prism (version 6.01, GraphPad Software, Inc., La Jolla, CA, USA) was used to obtain the statistical figures. Categorical data were summarized as percentages. The KolmogorovSmirnov test was used to test the normality of the variables. Variables that were not normally distributed were presented as medians (interquartile range) and continuous and normally distributed data were presented as means and standard deviations (SD). Differences were tested using the independent samples $t$-test. Correlations were analyzed using linear regression. All indices' intra- and interobserver variabilities were analyzed by determining the mean difference, intra-class correlation coefficient (ICC) and coefficient of variation $(\mathrm{CoV})$. A two-tailed $\mathrm{P}$ value $<0.05$ was defined as statistically significant.

\section{Results}

\section{Participant characteristics}

The demographic and biochemical data are summarized in Table 1. Two controls and four patients with T2DM were excluded due to poor image quality. Thirty-nine control subjects and 57 patients with T2DM were enrolled. Patients with T2DM (mean diabetes duration, $7.8 \pm 4.8$ years) were similar in gender, body surface area and blood pressure to the control subjects. The mean age $(54.9 \pm 8.0$ vs. $50.2 \pm 11.8$ years, $\mathrm{P}=0.021)$ and $\mathrm{BMI}\left(24.9 \pm 2.6\right.$ vs. $\left.23.8 \pm 2.7 \mathrm{~kg} / \mathrm{m}^{2}, \mathrm{P}=0.046\right)$ of the T2DM group was greater than that of the control group, respectively. Compared with controls, T2DM patients also showed higher triglycerides, glucose and HbAlc; lower HDL-C; and similar total cholesterol and LDL-C measurements. None of the subjects had valvular stenosis. All subjects had mild regurgitation.

\section{Effects of T2DM on RV function}

There was no significant difference in CMR-TAPSE between the T2DM patients and controls (T2DM, $19.8 \pm 4.7 \mathrm{~mm} v$ s. control, $18.7 \pm 4.6 \mathrm{~mm}, \mathrm{P}=0.234$ ) (Table 2).

Regarding LAS, T2DM patients had a smaller LAS of the epicardial apex of the $L V$ and the lateral insertion of the tricuspid valve (LAS-LVapex/peri) compared with controls (T2DM, $-17.4 \% \pm 4.2 \%$ vs. $-19.7 \% \pm 3.7 \%, \mathrm{P}=0.008$ ) (Figure 2) and a smaller LAS of the epicardial apex of the LV and the middle of the lateral insertion point and septum insertion point (LAS-LVapex/mid) (T2DM, $-17.5 \% \pm 4.5 \%$ vs. controls, $-19.5 \% \pm 3.9 \%, \mathrm{P}=0.026)$. However, T2DM patients had a similar LAS of the RV insertion between the RV and $L V$ and the lateral insertion of the tricuspid valve (LAS-ins/peri) (T2DM, $-20.7 \% \pm 10.6 \%$ vs. control, $-20.9 \% \pm 4.2 \%, P=0.891$ ) and a similar LAS of the RV insertion between the RV and $\mathrm{LV}$ and the middle of the lateral insertion point and septum insertion point (LAS$\mathrm{ins} / \mathrm{mid}$ ) (T2DM, $-20.3 \pm 4.5 \%$ vs. control, $-19.3 \% \pm 4.2 \%$, $\mathrm{P}=0.264$ ) (Table 2). After adjustments for age and BMI, T2DM was associated with LVapex/peri $(\mathrm{P}=0.028)$, but not with LVapex/mid $(\mathrm{P}=0.085)$.

There were no significant differences between T2DM patients and controls in CMR-TAPSE (T2DM, 18.7 $\pm 4.6 \mathrm{~mm}$ vs. control, $19.8 \pm 4.7 \mathrm{~mm}, \mathrm{P}=0.234)$ and $\mathrm{RV}$ global function, including EDVi (T2DM, $124.4 \pm 21.5 \mathrm{~mL} / \mathrm{m}^{2}$ vs. control, $\left.115.7 \pm 23.2 \mathrm{~mL} / \mathrm{m}^{2}, \mathrm{P}=0.066\right), \mathrm{ESVi}\left(\mathrm{T} 2 \mathrm{DM}, 57.1 \pm 14.9 \mathrm{~mL} / \mathrm{m}^{2}\right.$ vs. control, $\left.61.8 \pm 14.4 \mathrm{~mL} / \mathrm{m}^{2}, \mathrm{P}=0.131\right), \mathrm{SVi}(\mathrm{T} 2 \mathrm{DM}$, $58.6 \pm 10.2 \mathrm{~mL} / \mathrm{m}^{2} v s$. control, $\left.62.6 \pm 9.4 \mathrm{~mL} / \mathrm{m}^{2}, \mathrm{P}=0.053\right)$, EF (T2DM, $51.1 \pm 5.2 \%$ vs. control, $50.8 \pm 4.8 \%, \mathrm{P}=0.735)$ and RVCI (T2DM, 2.6 $\pm 0.5 \mathrm{~L} / \mathrm{min} / \mathrm{m}^{2}$ vs. control, $2.8 \pm 0.5 \mathrm{~L} / \mathrm{min} / \mathrm{m}^{2}, \mathrm{P}=0.131$ ) (Table 2).

There were no significant differences between T2DM patients and controls concerning all RV strains and strain rates (Table 2).

\section{Relationship between LAS and RV function}

In all participants, a reduced LAS-LVapex/peri was associated with a decreased CMR-TAPSE $(r=-0.723$, $\mathrm{P}<0.001)$, RVSV $(\mathrm{r}=-0.225, \mathrm{P}=0.028)$, RVEF $(\mathrm{r}=-0.270$, 
Table 1 Demographic and biochemical characteristics of all participants

\begin{tabular}{|c|c|c|c|}
\hline Demographic and biochemical characteristics & Control $(n=39)$ & T2DM $(n=57)$ & $P$ value \\
\hline Age, years & $50.2 \pm 11.8$ & $54.9 \pm 8.0$ & $0.021^{*}$ \\
\hline Diabetic duration, years & - & $7.8 \pm 4.8$ & - \\
\hline Male, n (\%) & 19 [49] & $25[44]$ & 0.639 \\
\hline Body surface area, $\mathrm{m}^{2}$ & $1.7 \pm 0.2$ & $1.7 \pm 0.2$ & 0.492 \\
\hline Systolic blood pressure, $\mathrm{mmHg}$ & $117.7 \pm 10.0$ & $119.9 \pm 10$ & 0.289 \\
\hline Diastolic blood pressure, $\mathrm{mmHg}$ & $80.1 \pm 7.1$ & $78.9 \pm 7.6$ & 0.473 \\
\hline \multicolumn{4}{|l|}{ Biochemical exam } \\
\hline HDL-C, $\mathrm{mmol} / \mathrm{L}$ & $1.4 \pm 0.4$ & $1.2 \pm 0.4$ & $0.018^{\star}$ \\
\hline $\mathrm{LDL}-\mathrm{C}, \mathrm{mmol} / \mathrm{L}$ & $3.5 \pm 1.3$ & $3.1 \pm 1.0$ & 0.195 \\
\hline Glucose, $\mathrm{mmol} / \mathrm{L}$ & $5.3[4.8-5.9]$ & $8.4[6.5-10.0]$ & $<0.001^{\star \star \star}$ \\
\hline Glycated hemoglobin, \% & $5.5[5.2-5.8]$ & $7.6[6.8-9.1]$ & $<0.001^{\star \star \star}$ \\
\hline \multicolumn{4}{|l|}{ Medications, n (\%) } \\
\hline ACEI & - & 7 [12] & - \\
\hline Statins & - & $27[47]$ & - \\
\hline Aspirin & - & $8[14]$ & - \\
\hline
\end{tabular}

*, $\mathrm{P}<0.05$; ${ }^{* \star *}, \mathrm{P}<0.001$. T2DM, type 2 diabetes mellitus; HDL-C, high-density lipoprotein cholesterol; LDL-C, low-density lipoprotein cholesterol; ACEI, angiotensin-converting enzyme inhibitors.

$\mathrm{P}=0.008$ ), peak longitudinal strain (PLS, $\mathrm{r}=0.210, \mathrm{P}=0.040$ ). A reduced LAS-LVapex/mid was associated with a decreased CMR-TAPSE $(\mathrm{r}=-0.665, \mathrm{P}<0.001)$, RVSV $(\mathrm{r}=-0.247$, $\mathrm{P}=0.015)$ and RVEF $(\mathrm{r}=-0.207, \mathrm{P}=0.043)$, but not with PLS $(\mathrm{r}=0.197, \mathrm{P}=0.054)$. LAS-LVapex/peri and LAS-LVapex/ mid were not associated with peak radial or circumferential strain. Besides, LAS-LVapex/peri and LAS-LVapex/mid were not associated with diabetic duration or glycated hemoglobin.

\section{Intra- and interobserver reproducibility}

A summary of the ICC values and mean differences in intraand interobserver reproducibility is shown in Table 3 and Table S1.

Of the four LAS indices, the ICCs of the intra-and interobserver reproducibility of LVapex/peri was the highest (0.912 and 0.933 , respectively); these were higher than the
ICCs for CMR-TAPSE (0.909 and 0.900), PLS (0.885 and $0.805)$ and RVEF (0.716 and 0.797).

\section{Discussion}

In this study, CMR cine was used to evaluate changes in RV function in patients with T2DM. There were four main findings. First, concerning LAS, LASapex/peri and LVapex/mid were decreased in T2DM patients, but only the decrease in LASapex/peri remained significant after adjusting for other factors. Second, LASapex/peri significantly correlated with RVEF, CMR-TAPSE and PLS. Third, there were no significant differences in RVEF, CMR-TAPSE and PLS between T2DM patients and controls. Finally, compared with the other three LAS indices and RVEF, CMR-TAPSE and PLS, LASapex/peri showed the highest intra- and interobserver reproducibility.

TAPSE is the most frequently used index to evaluate 
Table 2 RV LAS, CMR-TAPSE, global functions and strain for all participants

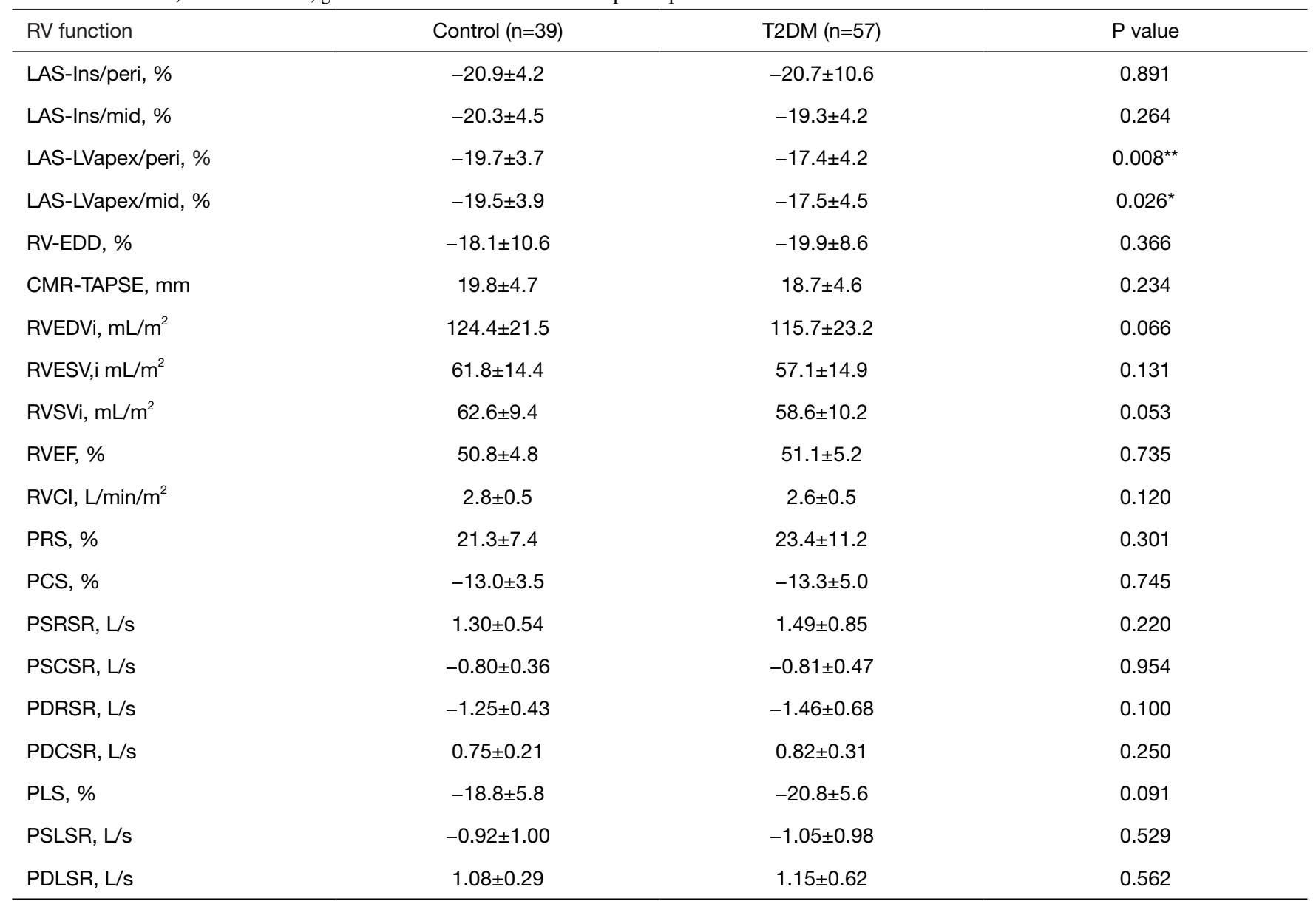

*, $\mathrm{P}<0.05 .{ }^{* \star}, \mathrm{P}<0.01$. RV, right ventricular; LAS, long-axis strain; CMR, cardiovascular magnetic resonance; TAPSE, tricuspid annular plane systolic excursion; LV, left ventricular; Ins, RV insertion between RV and LV; peri, lateral insertion of the tricuspid valve; LVapex, epicardial apex of the left ventricle; mid, the middle of the lateral insertion point and septum insertion point; ED, end-diastolic; EDD, the shortening percentage of the ED diameter; RVEDVi, right ventricular ED volume index; RVESVi, right ventricular ED volume index; RVSVi, right ventricular stroke volume index; RVEF, right ventricular ejection fraction; RVCI, cardiac index; PRS, peak radial strain; PCS, peak circumferential strain; PSRSR, peak systolic radial strain rate; PSCSR, peak systolic circumferential strain rate; PDRSR, peak diastolic radial strain rate; PDCSR, peak diastolic circumferential strain rate; PLS, peak longitudinal strain; PSLSR, peak systolic longitudinal strain rate; PDLSR, peak diastolic longitudinal strain rate.

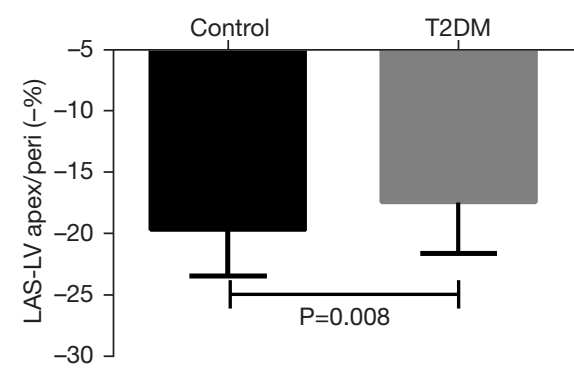

Figure 2 The difference in RV LAS (LVapex/peri) between patients with T2DM and controls. RV, right ventricular; LAS, long-axis strain; LV, left ventricular; T2DM, type 2 diabetes mellitus.
RV function in clinical settings and can be easily obtained using ultrasound and CMR $(13,14)$. Previous studies have shown a strong correlation between TAPSE and RVEF $(15,16)$. Additionally, CMR-TAPSE is used as an important indicator for the prognosis of many diseases $(7,17)$. In the present study, there were no significant differences in TAPSE between T2DM patients and controls. The reasons may be as follows: TAPSE is an absolute value that reflects the moving distance of the tricuspid ring between the diastolic and systolic phases. Individual differences can significantly affect the measurement of an absolute value instead of a relative value, limiting the sensitivity and 
Table 3 Intra- and interobserver reproducibility for main measurements of RV function

\begin{tabular}{|c|c|c|c|c|}
\hline RV function indices & \multicolumn{2}{|c|}{ Intraobserver } & \multicolumn{2}{|c|}{ Interobserver } \\
\hline LASapex/peri & $-0.6(-1.5,0.3)$ & $0.912(0.777,0.965)$ & $-1.1(-1.9,-0.3)$ & $0.933(0.831,0.973)$ \\
\hline CMR-TAPSE & $-0.7(-1.6,0.3)$ & $0.909(0.769,0.964)$ & $-0.5(-1.4,0.4)$ & $0.900(0.747,0.960)$ \\
\hline RVEF & $-0.2(-1.9,1.4)$ & $0.716(0.281,0.887)$ & $-0.1(-1.7,1.6)$ & $0.797(0.488,0.920)$ \\
\hline PCS & $-0.8(-2.0,0.3)$ & $0.839(0.592,0.936)$ & $-1.2(-2.1,-0.3)$ & $0.908(0.767,0.963)$ \\
\hline PLS & $1.2(-0.1,2.6)$ & $0.885(0.708,0.954)$ & $1.2(-0.7,3.0)$ & $0.805(0.508,0.923)$ \\
\hline
\end{tabular}

$\mathrm{Cl}$, confidence interval; ICC, intra-class correlation coefficient; LAS, long-axis strain; LVapex, epicardial apex of the left ventricle; peri, lateral insertion of the tricuspid valve; CMR, cardiovascular magnetic resonance; TAPSE, tricuspid annular plane systolic excursion; RVEF, right ventricular ejection fraction; PRS, peak radial strain; PCS, peak circumferential strain; PLS, peak longitudinal strain.

specificity of TAPSE measurements. Therefore, in this study, TAPSE may not be sufficiently sensitive to T2DMrelated RV changes.

In the present study, as an RV function index, LAS was measured in CMR four-chamber cine. LASapex/peri correlated well with RVEF and CMR-TAPSE, which is consistent with the studies of Arenja et al. (9) and Riffel et al. (10).

At present, whether PLS can sensitively reflect $\mathrm{RV}$ dysfunction is still controversial. In diseases that significantly affect $\mathrm{RV}$ function, such as arrhythmogenic RV cardiomyopathy, both echo-derived PLS $(18,19)$ and CMRderived PLS (20) is significantly reduced. Furthermore, in hypertrophic cardiomyopathy $(21,22)$ and heart failure (23), PLS measured by CMR is also significantly reduced. However, in diseases that may not significantly affect RV function, PLS may not be reduced.

Whether T2DM significantly reduces PLS remains controversial. In studies by $\mathrm{Ng}$ et al. (24) and Shao et al. (25), PLS was significantly reduced. However, Hwang et al. (26) reported no significant difference in PLS between T2DM and non-T2DM patients. In the present study, decreased PLS was not seen in patients with T2DM. The intraand interobserver reproducibility of PLS was quite low. It may be that because the RV wall itself is thin, it is difficult to track myocardial motion using either CMR cine or ultrasound $(27,28)$. In addition, concerning feature tracking postprocessing, besides tagging and strain-encoding (SENC) CMR, many commercial software programs perform CMR cine-based strain analyses, including Circle42 (29,30), TomTec, Medis, Neosoft, etc. However, differences have been observed in the processing results between these software programs (31). Consequently, there is no universally recognized post-processing software to calculate RV strain. Therefore, PLS might not be sufficiently sensitive to evaluate RV function, particularly in those diseases that affect RV function only slightly, such as T2DM.

Compared with healthy controls, T2DM patients showed decreased LASapex/peri and LVapex/mid indices; however, only the decrease in LASapex/peri remained significant after adjustment for other factors. One possible mechanism of T2DM-related RV subclinical dysfunction is that increased myocardial triglyceride content in T2DM (32) may contribute to the extensive impairment of $\mathrm{RV}$ function (24). Moreover, it has been shown in an animal study that therapeutic interventions that relieve myocardial triglyceride accumulation can lead to improvements in myocardial function (33). Additionally, the intra- and interobserver reproducibility were highest for LASapex/ peri. LAS is a relative index that considers individual differences and is derived from the apex of the LV and lateral insertion of the tricuspid valve on the end-diastolic and end-systolic phases. It is relatively simple and easily obtained in the clinic. Therefore, compared with CMRTAPSE, PLS and RVEF, LASapex/peri may be a more sensitive and more suitable index for assessing the decrease of RV function in patients with T2DM.

Our study had the following limitations. First, the overall number of subjects was relatively small. Second, the current study did not enroll age-matched patients. Although consecutive patients were enrolled, the older age of the T2DM patients compared with controls may have led to selection bias. A larger age-matched cohort will be needed 
in further research. Second, this is a cross-sectional study; the prognostic value of LAS should be determined in future studies. Finally, the patients with T2DM were receiving treatment, which may have affected the results.

\section{Conclusions}

The reproducibility and values of RV functional indices were studied in T2DM patients. Our results suggest that, compared with traditional RV functional indices, such as CMR-TAPSE, RVEF and PLS, LAS is easy to obtain and has high repeatability; furthermore, the LAS apex/lateral wall may be a more sensitive index of T2DM-related RV dysfunction.

\section{Acknowledgments}

Funding: This work was supported by the National Natural Science Foundation of China (grant number: 81971587) and the Natural Science Foundation of Chongqing (grant number: cstc2020jcyj-msxmX0399).

\section{Footnote}

Conflicts of Interest: All authors have completed the ICMJE uniform disclosure form (available at https://dx.doi. org/10.21037/qims-21-376). The authors have no conflicts of interest to declare.

Ethical Statement: The authors are accountable for all aspects of the work in ensuring that questions related to the accuracy or integrity of any part of the work are appropriately investigated and resolved. The study was conducted in accordance with the Declaration of Helsinki (as revised in 2013). The study was approved by the Ethics Committee of the First Affiliated Hospital of Third Military Medical University (scientific research No. 50; approval date: May 11, 2016), and informed consent was obtained from all patients.

Open Access Statement: This is an Open Access article distributed in accordance with the Creative Commons Attribution-NonCommercial-NoDerivs 4.0 International License (CC BY-NC-ND 4.0), which permits the noncommercial replication and distribution of the article with the strict proviso that no changes or edits are made and the original work is properly cited (including links to both the formal publication through the relevant DOI and the license).
See: https://creativecommons.org/licenses/by-nc-nd/4.0/.

\section{References}

1. Yang W, Lu J, Weng J, Jia W, Ji L, Xiao J, et al. Prevalence of diabetes among men and women in China. $\mathrm{N}$ Engl $\mathrm{J}$ Med 2010;362:1090-101.

2. Leng S, Dong Y, Wu Y, Zhao X, Ruan W, Zhang G, Allen JC, Koh AS, Tan RS, Yip JW, Tan JL, Chen Y, Zhong L. Impaired Cardiovascular Magnetic Resonance-Derived Rapid Semiautomated Right Atrial Longitudinal Strain Is Associated With Decompensated Hemodynamics in Pulmonary Arterial Hypertension. Circ Cardiovasc Imaging 2019;12:e008582.

3. Ouyang R, Leng S, Sun A, Wang Q, Hu L, Zhao X, Yan Q, Tan RS, Zhong L, Zhong Y. Detection of persistent systolic and diastolic abnormalities in asymptomatic pediatric repaired tetralogy of Fallot patients with preserved ejection fraction: a CMR feature tracking study. Eur Radiol 2021;31:6156-68.

4. Rajappan K, Bellenger NG, Anderson L, Pennell DJ. The role of cardiovascular magnetic resonance in heart failure. Eur J Heart Fail 2000;2:241-52.

5. Bonnemains L, Mandry D, Marie PY, Micard E, Chen B, Vuissoz PA. Assessment of right ventricle volumes and function by cardiac MRI: quantification of the regional and global interobserver variability. Magn Reson Med 2012;67:1740-6.

6. Leng S, Guo J, Tan RS, Chai P, Teo L, Fortier MV, Gong C, Zhao X, Ong CC, Allen JC, Ruan W, Koh AS, Tan TH, Yip JW, Tan JL, Chen Y, Zhong L. Age- and Sex-Specific Changes in CMR Feature Tracking-Based Right Atrial and Ventricular Functional Parameters in Healthy Asians. Front Cardiovasc Med 2021;8:664431.

7. Hoette S, Creuzé N, Günther S, Montani D, Savale L, Jaïs X, Parent F, Sitbon O, Rochitte CE, Simonneau G, Humbert M, Souza R, Chemla D. RV Fractional Area Change and TAPSE as Predictors of Severe Right Ventricular Dysfunction in Pulmonary Hypertension: A CMR Study. Lung 2018;196:157-64.

8. Alam M, Wardell J, Andersson E, Samad BA, Nordlander R. Right ventricular function in patients with first inferior myocardial infarction: assessment by tricuspid annular motion and tricuspid annular velocity. Am Heart J 2000;139:710-5.

9. Arenja N, Riffel JH, Djiokou CN, Andre F, Fritz T, Halder M, Zelniker T, Kristen AV, Korosoglou G, Katus HA, Buss SJ. Right ventricular long axis strain-validation of a novel 
parameter in non-ischemic dilated cardiomyopathy using standard cardiac magnetic resonance imaging. Eur J Radiol 2016;85:1322-8.

10. Riffel JH, Andre F, Maertens M, Rost F, Keller MG, Giusca S, Seitz S, Kristen AV, Müller M, Giannitsis E, Korosoglou G, Katus HA, Buss SJ. Fast assessment of long axis strain with standard cardiovascular magnetic resonance: a validation study of a novel parameter with reference values. J Cardiovasc Magn Reson 2015;17:69.

11. Alberti KG, Zimmet PZ. Definition, diagnosis and classification of diabetes mellitus and its complications. Part 1: diagnosis and classification of diabetes mellitus provisional report of a WHO consultation. Diabet Med 1998;15:539-53.

12. Lang RM, Badano LP, Mor-Avi V, Afilalo J, Armstrong A, Ernande L, Flachskampf FA, Foster E, Goldstein SA, Kuznetsova T, Lancellotti P, Muraru D, Picard MH, Rietzschel ER, Rudski L, Spencer KT, Tsang W, Voigt JU. Recommendations for cardiac chamber quantification by echocardiography in adults: an update from the American Society of Echocardiography and the European Association of Cardiovascular Imaging. J Am Soc Echocardiogr 2015;28:1-39.e14.

13. Sepúlveda-Martínez A, Steding-Ehrenborg K, RodríguezLópez M, Ostenfeld E, Valenzuela-Alcaráz B, Heiberg E, Gratacós E, Prat-González S, Crispi F, Hedström E. Atrioventricular plane displacement versus mitral and tricuspid annular plane systolic excursion: A comparison between cardiac magnetic resonance and M-mode echocardiography. Clin Physiol Funct Imaging 2021;41:262-70.

14. Evaldsson AW, Lindholm A, Jumatate R, Ingvarsson A, Smith GJ, Waktare J, Rådegran G, Roijer A, Meurling C, Ostenfeld E. Right ventricular function parameters in pulmonary hypertension: echocardiography vs. cardiac magnetic resonance. BMC Cardiovasc Disord 2020;20:259.

15. Zhao H, Kang Y, Pickle J, Wang J, Han Y. Tricuspid annular plane systolic excursion is dependent on right ventricular volume in addition to function. Echocardiography 2019;36:1459-66.

16. Werther Evaldsson A, Ingvarsson A, Smith JG, Rådegran G, Roijer A, Waktare J, Ostenfeld E, Meurling C. Echocardiographic right ventricular strain from multiple apical views is superior for assessment of right ventricular systolic function. Clin Physiol Funct Imaging 2019;39:168-76.

17. Ochs MM, Fritz T, Arenja N, Riffel J, Andre F, Mereles D, Siepen FAD, Hegenbart U, Schönland S, Katus
HA, Friedrich MGW, Buss SJ. Regional differences in prognostic value of cardiac valve plane displacement in systemic light-chain amyloidosis. J Cardiovasc Magn Reson 2017;19:87.

18. Teske AJ, Cox MG, Te Riele AS, De Boeck BW, Doevendans PA, Hauer RN, Cramer MJ. Early detection of regional functional abnormalities in asymptomatic ARVD/C gene carriers. J Am Soc Echocardiogr 2012;25:997-1006.

19. Aneq MÅ, Engvall J, Brudin L, Nylander E. Evaluation of right and left ventricular function using speckle tracking echocardiography in patients with arrhythmogenic right ventricular cardiomyopathy and their first degree relatives. Cardiovasc Ultrasound 2012;10:37.

20. Heermann P, Hedderich DM, Paul M, Schülke C, Kroeger JR, Baeßler B, Wichter T, Maintz D, Waltenberger J, Heindel W, Bunck AC. Biventricular myocardial strain analysis in patients with arrhythmogenic right ventricular cardiomyopathy (ARVC) using cardiovascular magnetic resonance feature tracking. J Cardiovasc Magn Reson 2014;16:75.

21. Yang L, Zhang L, Cao S, Gao C, Xu H, Song T, Zhang $\mathrm{X}$, Wang K. Advanced myocardial characterization in hypertrophic cardiomyopathy: feasibility of CMR-based feature tracking strain analysis in a case-control study. Eur Radiol 2020;30:6118-28.

22. Afonso L, Briasoulis A, Mahajan N, Kondur A, Siddiqui F, Siddiqui S, Alesh I, Cardozo S, Kottam A. Comparison of right ventricular contractile abnormalities in hypertrophic cardiomyopathy versus hypertensive heart disease using two dimensional strain imaging: a cross-sectional study. Int J Cardiovasc Imaging 2015;31:1503-9.

23. Houard L, Benaets MB, de Meester de Ravenstein C, Rousseau MF, Ahn SA, Amzulescu MS, Roy C, Slimani A, Vancraeynest D, Pasquet A, Vanoverschelde JJ, Pouleur AC, Gerber BL. Additional Prognostic Value of 2D Right Ventricular Speckle-Tracking Strain for Prediction of Survival in Heart Failure and Reduced Ejection Fraction: A Comparative Study With Cardiac Magnetic Resonance. JACC Cardiovasc Imaging 2019;12:2373-85.

24. Ng AC, Delgado V, Bertini M, van der Meer RW, Rijzewijk LJ, Hooi Ewe S, Siebelink HM, Smit JW, Diamant M, Romijn JA, de Roos A, Leung DY, Lamb HJ, Bax JJ. Myocardial steatosis and biventricular strain and strain rate imaging in patients with type 2 diabetes mellitus. Circulation 2010;122:2538-44.

25. Shao G, Cao Y, Cui Y, Han X, Liu J, Li Y, Li N, Liu T, Yu J, Shi H. Early detection of left atrial and bi- 
ventricular myocardial strain abnormalities by MRI feature tracking in normotensive or hypertensive T2DM patients with preserved LV function. BMC Cardiovasc Disord 2020;20:196.

26. Hwang JW, Cha MJ, Kim SM, Kim Y, Choe YH. Relationship between cardiovascular risk factors and myocardial strain values of both ventricles in asymptomatic Asian subjects: measurement using cardiovascular magnetic resonance tissue tracking. Int J Cardiovasc Imaging 2018;34:1949-57.

27. Qu YY, Li H, Rottbauer W, Ma GS, Buckert D, Rasche V. Right ventricular free wall longitudinal strain and strain rate quantification with cardiovascular magnetic resonance based tissue tracking. Int J Cardiovasc Imaging 2020;36:1985-96.

28. Zaidi A, Knight DS, Augustine DX, Harkness A, Oxborough D, Pearce K, Ring L, Robinson S, Stout M, Willis J, Sharma V; Education Committee of the British Society of Echocardiography. Echocardiographic assessment of the right heart in adults: a practical guideline from the British Society of Echocardiography Echo Res Pract 2020;7:G19-41.

29. Huo H, Dai X, Li S, Zheng Y, Zhou J, Song Y, Liu S, Hou Y, Liu T. Diagnostic accuracy of cardiac magnetic

Cite this article as: Shang Y, Zhang Y, Leng W, Lei X, Chen L, Zhou X, Liang Z, Wang J. Assessment of right ventricular function using cardiovascular magnetic resonance in patients with type 2 diabetes mellitus. Quant Imaging Med Surg 2022;12(2):1539-1548. doi: 10.21037/qims-21-376 resonance tissue tracking technology for differentiating between acute and chronic myocardial infarction. Quant Imaging Med Surg 2021;11:3070-81.

30. Wang L, Liu M, Zhang PY, Dai JZ, Ma HY, Tao XC, Xie WM, Wan J, Jing A. Analysis of right ventricular flow with 4-dimensional flow cardiovascular magnetic resonance imaging in patients with pulmonary arterial hypertension. Quant Imaging Med Surg 2021;11:3655-65.

31. Backhaus SJ, Metschies G, Zieschang V, Erley J, Mahsa Zamani S, Kowallick JT, Lapinskas T, Pieske B, Lotz J, Kutty S, Hasenfuß G, Kelle S, Schuster A. Head-to-head comparison of cardiovascular MR feature tracking cine versus acquisition-based deformation strain imaging using myocardial tagging and strain encoding. Magn Reson Med 2021;85:357-68.

32. Rijzewijk LJ, van der Meer RW, Smit JW, Diamant $M$, Bax JJ, Hammer S, Romijn JA, de Roos A, Lamb HJ. Myocardial steatosis is an independent predictor of diastolic dysfunction in type 2 diabetes mellitus. J Am Coll Cardiol 2008;52:1793-9.

33. Zhou Y'T, Grayburn P, Karim A, Shimabukuro M, Higa M, Baetens D, Orci L, Unger RH. Lipotoxic heart disease in obese rats: implications for human obesity. Proc Natl Acad Sci U S A 2000;97:1784-9. 
Supplementary

Table S1 Intra- and interobserver reproducibility for all measurements of RV function

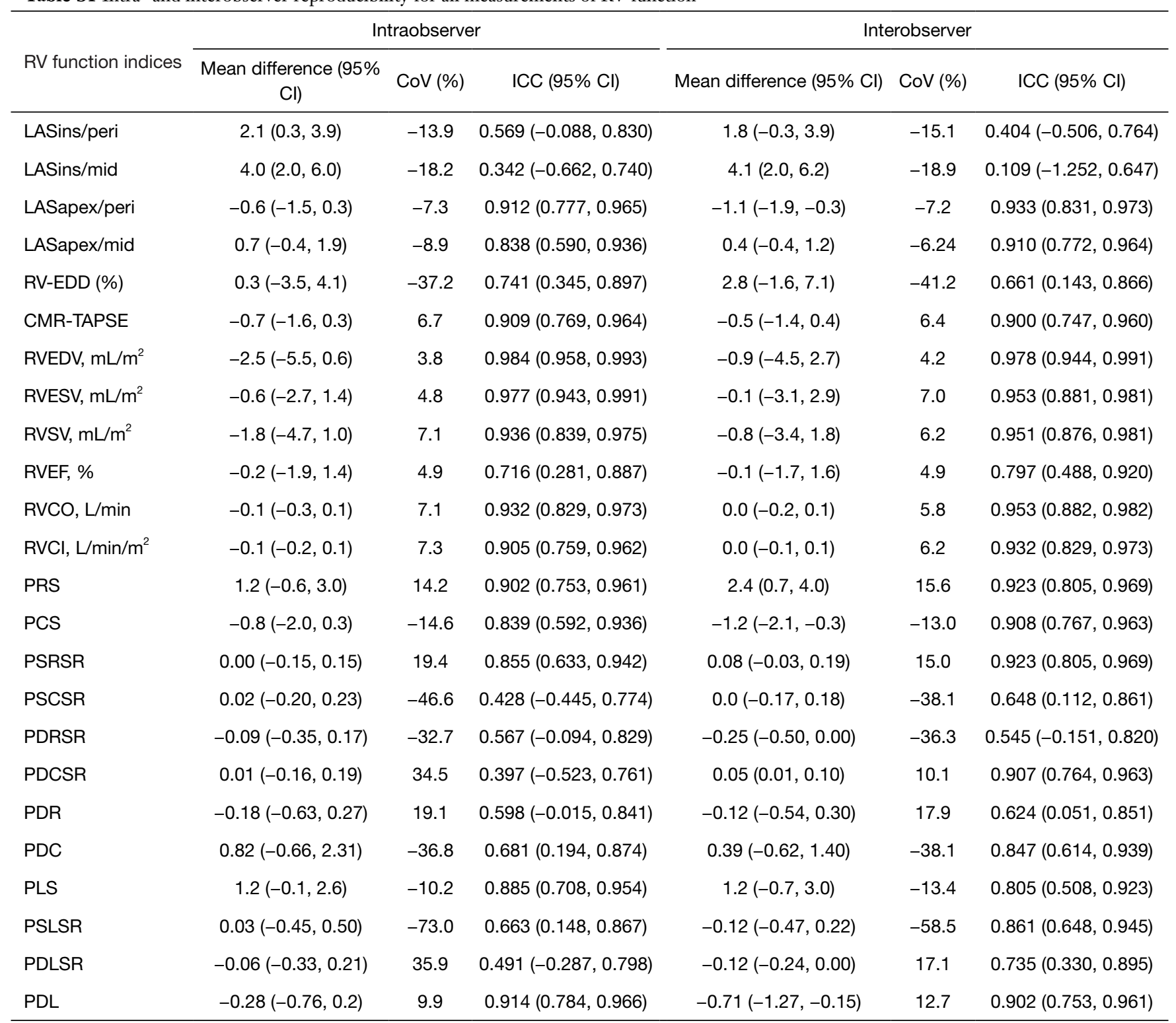

$\mathrm{Cl}$, confidence interval; CoV, coefficient of variation; ICC, intra-class correlation coefficient; LAS, long-axis strain; LV, left ventricular; RV, right ventricular; Ins, RV insertion between RV and LV; peri, lateral insertion of the tricuspid valve; LVapex, epicardial apex of the left ventricular; mid, the middle of the lateral insertion point and septum insertion point; ED, end-diastolic; EDD, the shortening percentage of the end-diastolic diameter; TAPSE, tricuspid annular plane systolic excursion; RVEDVi, right ventricular ED volume index; RVESVi, right ventricular end-systolic volume index; RVSVi, right ventricular stroke volume index; RVEF, right ventricular ejection fraction; RVCI, right ventricular cardiac index, PRS, peak radial strain; PCS, peak circumferential strain; PSRSR, peak systolic radial strain rate; PSCSR, peak systolic circumferential strain rate; PDRSR, peak diastolic radial strain rate; PDCSR, peak diastolic circumferential strain rate; PLS, peak longitudinal strain; PSLSR, peak systolic longitudinal strain rate; PDLSR, peak diastolic longitudinal strain rate. 